\title{
ERYTHROCYTE STEARIC TO OLEIC ACID RATIO IN PATIENTS WITH OCULAR MELANOMA
}

\author{
W. A. ACLIMANDOS, ${ }^{1-4}$ D. HEINEMANN, S. B. KELLY, ${ }^{2}$ G. A. K. SHERAIDAH, ${ }^{3}$ J. L. \\ HUNGERFORD ${ }^{4}$ \\ London
}

\begin{abstract}
SUMMARY
The main characteristics of malignant cells include increased metabolism and capacity for division which are associated with high membrane fluidity. ${ }^{1}$ Membrane fluidity is in turn controlled by multiple factors which include the ratio of saturated to unsaturated fatty acids in the cell wall i.e. the Saturation Index (SI). ${ }^{2-3}$ The SI is known to be reduced in neoplastic cells as well as in the circulating erythrocytes of patients with some malignant tumours but not others. It has been suggested that the SI may be useful as a marker of malignancy.
\end{abstract}

Erythrocyte fatty acid profiles were determined by gas liquid chromatography in 23 patients with benign eye diseases and 19 patients with ocular melanoma. The erythrocyte SI was lower in patients with ocular melanoma (mean 0.65 , range $0.30-1.04)$ then in patients with benign eye disease (mean 1.01, range 0.84-1.24) $(\mathrm{P}<0.001)$. This SI may be useful as a means of differentiating between patients with benign and malignant ocular disease.

Melanoma is the most common primary intraocular malignancy and has a high incidence of metastases, especially to the liver. ${ }^{4}$ Approximately half of the patients will die from the disease within 10-15 years of enucleation, ${ }^{5.6}$ and late metastases are not uncommon. ${ }^{6}$ The median survival following diagnosis of hepatic metastases is two to four months. ${ }^{7,8}$ Despite diagnostic and therapeutic advances the incidence and mortality rates of uveal melanoma have been shown to be fairly stable over the last several decades. ${ }^{9,10}$ There is a need for better indices which could provide guidance for the diagnosis, assessment and management of patients with ocular melanoma in the hope of improving their prognosis.

From: 'Ophthalmic Department, King's College Hospital, London, ${ }^{2}$ Department of Surgery, Royal Postgraduate Medical School, Hammersmith Hospital, London, ${ }^{3}$ Institute of Ophthalmology, London, and ${ }^{4}$ Moorfield's Eye Hospital, London.

Correspondence to: Mr W. A. Aclimandos, Ophthalmic Department, King's College Hospital, Denmark Hil
The stearic to oleic acid ratio (Saturation Index, SI) is known to be reduced in the membranes of some types of neoplastic cells. ${ }^{11,12}$ It has been shown that the erythrocyte SI is low in patients with various solid tumours ${ }^{13}$ and in patients with chronic leukaemia ${ }^{14}$ when compared to normal healthy subjects. It is believed that the SI is altered by factors secreted by the tumour into the systemic circulation. ${ }^{16}$ In other tumours like hepatoma ${ }^{12}$ the erythrocyte SI is not reduced. It has been shown that the erythrocyte SI is lower in patients with recurrent cancer compared to those with no evidence of recurrence ${ }^{13,15}$ It has therefore been suggested that the SI could be a useful marker for the diagnosis and postoperative monitoring of patients with some malignant tumours. However, it has recently been demonstrated that although erythrocyte SI is lower in patients with primary and recurrent colorectal cancer compared to controls and patients with inflammatory bowel disease or benign colonic polyps, it was not helpful in the postoperative follow-up of these patients as it did not correlate with their clinical progress. ${ }^{17}$ Some workers, ${ }^{18-20}$ have not been able to demonstrate a decrease in the erythrocyte SI of cancer patients but it is not possible to compare the results of various groups since each used a different method for lipid extraction.

The aim of this study is to investigate whether the erythrocyte SI is reduced in patients with ocular melanoma.

\section{PATIENTS AND METHODS}

Nineteen patients with ocular melanoma were studied ( $\mathrm{M}: \mathrm{F}=8: 11$; mean age 58 years, range 21-71 years). There were 16 patients with choroidal melanoma, two patients with melanoma of the iris and one patient with recurrent conjunctival melanoma. In the patients with choroidal melanoma, eight patients were treated by enucleation, five by radioactive plaques and the remaining three were being observed without any treatment. The patient with conjunctival melanoma underwent excision of local recurrence. One patient with melanoma of the iris had the lesion 
excised and remains under follow-up while the other patient developed multiple metastases and subsequently died. None of the patients included in this study was jaundiced at the time of testing.

The control group consisted of patients with benign diseases and were matched for age and sex with the melanoma group $(\mathrm{n}=23 ; \mathrm{M}: \mathrm{F}$ 12:11; mean age 57 years, range 24-76 years). These consisted of 19 patients with cataract, two patients with uveitis and two patients with ocular hypertension.

Five millilitres of venous blood were collected from each patient in an EDTA bottle and centrifuged at 1,500 $\mathrm{rpm}$ for five minutes to separate the erythrocytes. The plasma was discarded and the erythrocytes were washed three times with phosphate buffered saline (PBS). Following this, the erythrocytes were diluted 1:5 with PBS. This was performed within three hours of venepuncture. An identical procedure was followed for all melanoma and control samples in order to avoid the potential aberrations that could result from variable delays in the processing. The analyses were undertaken by the same technician who was unaware of the diagnosis at the time of analysis. The lipids were extracted from the erythrocytes by the method described by Folch et al. ${ }^{21}$ The erythrocyte suspension $(0.1 \mathrm{ml})$ was added to $0.5 \mathrm{ml}$ of methanol and mixed for 45 seconds. Following this, $1.4 \mathrm{ml}$ of freshly prepared methanol:chloroform (2:19) was added to the solution, which was mixed again. Methanol $(0.42 \mathrm{ml})$ was added and the solution was again mixed and then centrifuged at 1,000 rmp for 10 minutes. After this, as much of the upper phase as possible was extracted into a new tube. Chloroform $(0.7 \mathrm{ml})$ and water $(0.6 \mathrm{ml})$ were added and the solution was mixed again following which it was centrifuged at 1,000 rpm for 10 minutes. The upper phase was then removed and discarded three times, each time washing with $1.0 \mathrm{ml}$ of pure upper phase solvents (chloroform:methanol:distilled water at a ratio of 3:48:47). Finally, methanol $(0.2 \mathrm{ml})$ was added to clear the solution, which was then dried down under nitrogen on a sample concentrator.

The fatty acids were then extracted from the lipids by the method described by MacGee et al. ${ }^{19}$ The lipids were saponified by the additin of $15 \%$ methanolic potassium hydroxide $(1.0 \mathrm{ml})$ and the solution was mixed. Each specimen was then incubated at $65^{\circ} \mathrm{C}$ for 15 minutes, shaken by hand and re-incubated at $65^{\circ} \mathrm{C}$ for a further 15 minutes, after which it was allowed to cool. Distilled water $(1.0 \mathrm{ml})$ was added, followed by $4 \mathrm{~N}$ hydrochloric acid $(0.6 \mathrm{ml})$ and the solution was mixed again. The hydrochloric acid liberated free fatty acids from the potassium salts of the fatty acids, which were then extracted in $2.0 \mathrm{ml}$ of benzene, following which the solution was mixed and then centrifuged at 1,000 rpm for ten minutes. The bottom phase was then discarded.

Finally, the free fatty acids were methylated by the method described by Morrison and Smith. ${ }^{20}$ Boron trichloride in methanol $(1.0 \mathrm{ml})$ was added to the solution, following which it was mixed and then incubated at $100^{\circ} \mathrm{C}$ for ten minutes. After allowing the solution to cool to room temperature, distilled water $(2.0 \mathrm{ml})$ was added. The solution was mixed again and then centrifuged at 1,000 rpm for ten minutes. Following this, some of the upper (organic) phase was dried down under nitrogen, removed into a capsule and then dried down completely under nitrogen. It was then re-dissolved in six drops of trimethylpentane and stored at $-20^{\circ} \mathrm{C}$ until analysed by gas liquid chromatography.

The fatty acid methyl esters were analysed by temperature-programmed $\left(160-260^{\circ} \mathrm{C}\right.$ at $\left.4^{\circ} \mathrm{C} / \mathrm{min}\right)$ gas liquid chromatography, using a $2 \mathrm{~m} \times 2 \mathrm{~mm}$ internal diameter glass column packed with 3\% SP-2310/2\% SP-2300 on 100/120 mesh chromosorb W (Supelco Inc.). This gives a computer print out, which gives a completely objective means of measuring the percentage of each fatty acid present. The various peaks represent different fatty acids. The computer was programmed to measure the area under each peak. The percentage of each fatty acid present was determined from the percentage of each peak area compared to the total peak area. The ratio of stearic to oleic acid was taken from the chromatogram and expressed as the saturation index (SI). Statistical analysis was by an unpaired $t$ test. Ethical committee approval for the study was obtained and the nature of the study was fully explained to the patients concerned.

\section{RESULTS}

The mean erythrocyte SI was 0.65 (range $0.30-1.04$ ) in the melanoma group compared to 1.01 (range 0.84-1.24) in the control group (Fig. 1) $(\mathrm{P}<0.001)$. The erythrocyte SI in the patient with iris melanoma and multiple metastases (0.36) was near the lower end of the range. This patient was found to have multiple metastses within a few months

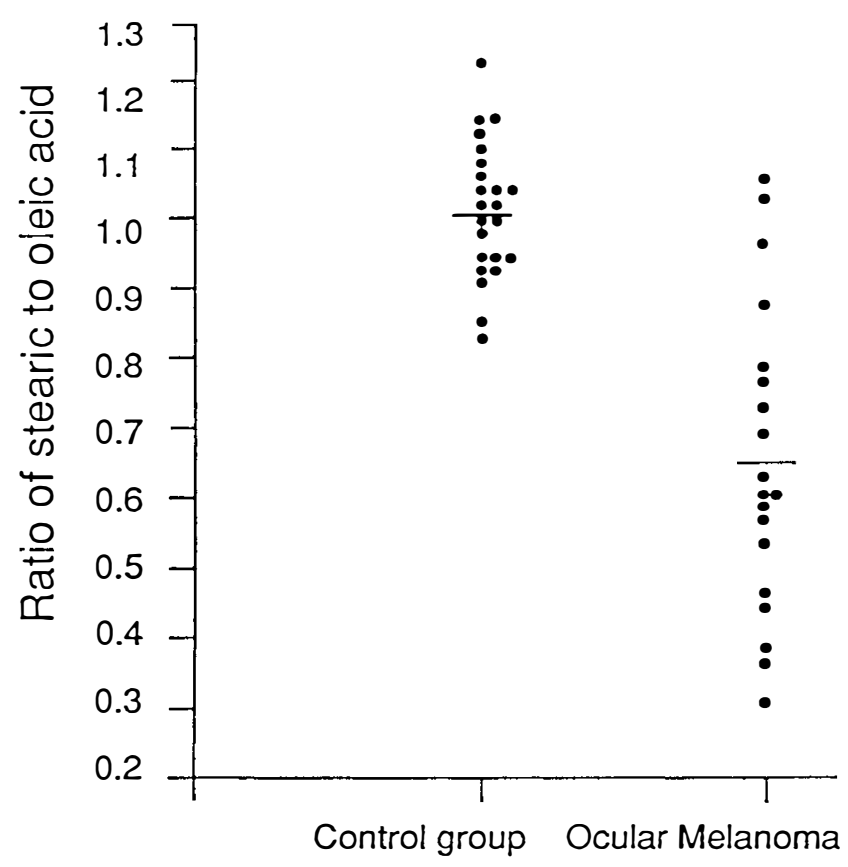

Fig. 1. Ratio of stearic to oleic acid in patients with ocular melanoma and benign eye disease (individual values (.) and means (-)). 
of diagnosis and died ten months later. Two patients, who at the time of enucleation had an erythrocyte SI of 0.60 and 0.62 respectively, were assessed again six months later and their erythrocyte SI had increased to 0.87 and 0.94 respectively.

Using the saturation index as a means of differentiating between patients with ocular melanoma and normal subjects, the sensitivity is $84.2 \%$ and the specificity is $91.3 \%$ when 0.92 is taken as a cut off point (which is equal to the mean minus one standard deviation: 0.09 ). The positive predictive value is $88.9 \%$ and the negative predictive value is $87.5 \%$

\section{DISCUSSION}

The demonstration of a low erythrocyte stearic to oleic acid ratio (SI) in patients with ocular melanoma compared to patients with benign eye diseases suggests that this tumour does, in this aspect, behave similarly to other neoplasms which reduce the $\mathrm{SI}^{3}$ as opposed to those which do not ${ }^{12}$ Despite their small mass ocular melanomas are associated with a widespread effect on the red blood cells which could be used as a tumour marker. It has been postulated that this phenomenon might be caused by the release of a desaturation producing factor by the tumour which acts as a catalyst for Delta-9-desaturase enzymes, or that the tumour could be releasing growth factors which affect the red blood cells progenitors. ${ }^{13}$ The erthyrocyte SI could be used to differentiate between benign and malignant choroidal lesions. If the SI reflects the mitotic activity of the tumour it could help to assess its malignant potential. It could also be of value in monitoring the progress of the disease in patients who are being reviewed or have had treatment such as enucleation or radiotherapy. If the SI is checked at regular intervals it might signal a recurrence or a metastasis before it becomes clinically obvious.

There are some limitations to the use of the SI measurement as a clinical tool. The procedure is complex and requires gas liquid chromatography as well as a specially trained technician. Reduction in the erythrocyte SI occurs in patients with various other tumours and therefore this marker may not help to differentiate between ocular melanoma and choroidal metastases. The erythrocyte SI is also reduced in diabetics ${ }^{26}$ and in jaundiced patients ${ }^{27}$ probably because of altered lipid metabolism.

The usefulness of this tumour marker will be verified and its predictive value further assessed by long-term review of patients in whom the erythrocyte SI is known.

We are grateful to Mrs E Cobb for her help in typing this manuscript. We are indebted to Professor A. C. Bird, Moorfields Eye Hospital, for his guidance and advice.

Key words: Erythrocyte stearic oleic acid ratio, Ocular melanoma.

\section{REFERENCES}

1. Sandemann H Jr: Regulation of membrane enzymes by lipids. Biochem Biophys Acta. 1979, 515: 209-37.

2. Doi O, Doi F, Schroeder F, Alberts S.W, Vangelos P:
Manipulation of fatty acid composition of membrane phospholipid and its effect on cell growth in mouse $\mathrm{L} \mathbf{M}$ cells. Biochem. Biophys. Acta. 1978, 509: 239-50.

3. Ip SHC, and Cooper R.A: Decreased membrane fluidity during differentiation of human promyelocytic leukaemia cells in culture. Blood. 1980, 56: 227-32.

4. Egan KM, Seddon JM, Glynn RJ, Gragoudas ES, Albert DM: Epidemiological aspects of uveal melanoma. Surv Ophthalmol 1988, 32: 239-51.

5. Jensen OA: Malignant melanomas of the human uvea: 25 follow-up cases in Denmark. Acta Ophthalmol 1982, 60: 161-82.

6. Raivio I: Uveal melanoma in Finland: An epidemiological, clinical, histological and prognostic study. Acta Ophthalmol (Suppl) (Kbh) 1977, 133: 1-64.

7. Rajpal S, Moore R, Karakousis CP: Survival in metastatic ocular melanoma. Cancer 1983, 52: 334-36.

8. Seddon JM, Albert DM, Lavin PT, Robinson N: A prognostic factor study of disease-free interval and survival following enucleation for uveal melanoma. Acta Ophthalmol 1983, 10: 1894-9.

9. Jensen OA. and Prause JU: Malignant melanomas of the human uvea in Denmark. Incidence and a 25 year follow-up of cases diagnosed between 1943 and 1952. In Lomatzsch PK, Blodi FC. Eds. Intraocular tumours, Berlin. SpringerVerlag 1982. 85-92.

10. Strickland D and Lee JA: Melanomas of the eye: stability of rates. Am J Epidemiol 1981, 113: 700-2.

11. Wood CB, Habib NA, Apostolov K, Thompson A, Barker W, Hershman M, Blumgart LH: Reduction in the stearic to oleic acid ratio in human malignant liver neoplasms. Eur $J$ Surg Oncol 1985, 11: 347-8.

12. Wood R, Upreti GC, de Antueno RJ: A comparison of lipid from liver and hepatoma subcellular membranes. Lipids 1986, 21: 292-300.

13. Wood CB, Habib NA, Thompson A, Bradpiece H, Smadja C, Hershman M, Barker W, Apostolov K: Increase of oleic acid in erythrocytes associated with malignancies. Br Med J 1985, 291: 163-5.

14. Apostolov K, Barker W, Catovsky D, Goldman J, Matutes E: Reduction in the stearic to oleic acid ratio in leukaemic cells - a possible chemical marker of malignancy. Blut 1985, 50: 349-54.

15. Wood CB, Habib NA, Apostolov K, Kersten D, Barker W, Smadja C, Thompson A, Blount M: Reduction in the stearic to oleic acid ratio in the circulating red blood cells: a possible tumour marker in solid human neoplasms. Eur J Surg Oncol 1985, 11: 167-9.

16. Habib NA, Hershman MJ, Apostolov K, Barker W, Smadja C, Wood CB: Desaturation of cell membrane fatty acids by urine from patients with cancer. Surg Res Comm 1987, 1: 111-14

17. Kelly SB, Miller J, Wood CB, Williamson RCN, Habib NA: Erythrocyte stearic acid desaturation in patients with colorectal carcinoma. Dis Col \& Rect 1990, 33: 1026-30.

18. Neoptolemos JP, Heagerty AM, Nicholson M, James RFL, Clayton H, Bell PRF: Inadequacy of oleic acid in erythrocytes as a marker of malignancies. $B r$ Med $J$ 1987, 294: 1157-8.

19. Neoptolemos JP, Clayton H, Heagerty AM, Nicholson MJ, Johnson B, Mason J, Manson K, James RFL, Bell PRF: Dietary fat in relation to fatty acid composition of red cells and adipose tissue in colorectal cancer. Br J Cancer 1988, 58: 575-9.

20. Thomas BS, O'Dea J, Fentiman IS: Erythrocyte membrane stearic and oleic acid ratios in breast cancer. Br J Surg 1988. 75: 1078-79.

21. Folch J, Lees M, Sloane Stanley GH: A simple method for the isolation and purification of total lipids from animal tissues. J Biol Chem 1957, 226: 497-509. 
22. MacGee $J$ and Allen KG: Preparation of methyl esters from the saponifiable fatty acids in small biological specimens for gas-liquid chromatographic analysis. J Chromatography 1974, 100: 35-42.

23. Morrison WR and Smith LM: Preparation of fatty acid methyl esters and dimethylacetals from lipids with boron fluoride-methanol. J Lipid Res 1964, 5: 600-8.

24. Petitou M, Tuy F, Rosenfield C, Mishal Z, Paintrand M, Jansin C, Mathe G, Inbar M: Decreased microviscosity of membrane lipis in leukaemic cells: two possible mechanisms. Proc. Net. Acad. Sci. USA. 1978, 75: 2306.
25. Soreide O, Bakken AM, Lygre T, Farstad M: Inadequacy of oleic acid in erythrocytes as a marker for malignancies. $\mathrm{Br}$ Med J 1987, 294: 548.

26. Tilvis RS, Miettinen TA: Fatty acid compositions of serum lipids, erythrocytes, and platelets in insulin dependent diabetic women. J Clin Endocrinol Metab 1985, 61: 741-5.

27. Habib NA, Hershman MJ, Smadja C, Wood CB, Barker W, Apostolov K: Erythrocyte stearic acid desaturation in patients with benign and malignant liver conditions. Surg Res Comm 1987, 1: 37-9. 